\title{
WEB BASED MANAGEMENT SYSTEM FOR ENACTUS MALAYSIA NATIONAL CUP (E-EMNC)
}

\section{Seah Choon Sen, Hanayanti Hafit, Shahreen Kasim, Mohd Farhan Md Fudzee, Azizul Azhar Ramli, Hairulnizam Mahdin}

Faculty of Computer Faculty Computer Science \& Information Technology, University Tun Hussein Onn Malaysia, Johor, Malaysia seanseah0702@gmail.com, \{hana, shahreen, farhan, azizulr, hairuln\}@ uthm.edu.my

This is an open access article distributed under the Creative Commons Attribution License, which permits unrestricted use, distribution, and reproduction in any medium, provided the original work is properly cited.

\section{ARTICLE DETAILS}

Article history:

Received 22 January 2017

Accepted 03 February 2017

Available online 05 February 2017

Keywords:

Event Management System, EMNC

\begin{abstract}
Web Based Management System of Enactus Malaysia National Cup (E-EMNC) is event management system that specially designed for the uses of Enactus Malaysia National Cup. Without a proper event management system, Enactus Malaysia National Cup cannot be perfect enough due to several outburst issues such as miss update of payment, long queue at registration counter, misunderstand of information and others. Thus, this event management system was developed to overcome most of the problem that occurs before, during and after the events. Related objectives are stated to solve the problem. System Development Life Cycle Waterfall model is used as the methodology to develop this system. This system is developed by using PHP as server-side scripting and Bootstrap as front end framework. The prototype of the system was considered success because it could navigate student leader to complete submit the report by shown the flow of system. This system is expected to lighten the burden of event committees and educated team leader on filing document through internet.
\end{abstract}

\section{Introduction}

The diversity of infrastructure programs around the world requires fully customized system functions and applications for effective planning, construction, and operations [1]. Through online system, clients can request service from the specific server to complete the specific task. Web-based management systems address basic management and control processes [1]

Enactus Malaysia Foundation (EMF) is organizing Enactus Malaysia National Cup (EMNC) every year. EMNC are dramatic, energy filled events where Enactus teams showcase the collective impact of their community outreach efforts. Student present their projects and are evaluated by business leaders serving as judges who rank them on how successful they were at using business concepts to improve the quality of life and standards of living for those in need [2]. EMNC is the biggest event for Enactus Malaysia and EMF are finding the way to keep the standard of managing this event. Therefore, E-EMNC is specially build based on the needs of EMNC.

EMF would organize Enactus Malaysia National Cup (EMNC) every year in different conventional center. This is a large event that accommodated more than two thousand people. Since the crews are limited in the registration counter and the name list is in document form, so some mistake and redundancy of registration list happened frequently. Due to this problem, the organization of EMF decided to develop an online management system specific for EMNC. Therefore, this paper is focused on developing a web based management system of Enactus Malaysia National Cup.

The objectives of the project are:

- To design a functional module based on EMNC requirement.

- To upgrade the functionality of current management system.

- To develop a specific online management system for EMNC.

This management system was build based on the needs of EMNC. It is specifically designed to solved the problem that faced by event committee and participant during EMNC. This system includes data update, registration management, and review report.

\section{Literature Review}

This literature review consists of research analysis and brief details regarding to the management system. During the development of web based event management system for Enactus Malaysia National Cup, the main components are the registration and management system which will be discussed in this section. Three similar systems were reviewed and comparisons of the similar systems were done to analyze the pros and cons of this system.

Eventbrite provides cost-effective event management software to help businesses organize and sell tickets to events online-while helping people discover events that fuel their passions. Eventbrite consist of multiple events and specific entire events which have different features. In the website, it shows the features, cased study, cooperated organizers, and registration form. By searching the events, there are multiple events that can be joined by users. The events are arranged according to category, event type, date and price. Basic features such as event details, ticket information, registration, attendee list are provided for free users.

The National Basketball Association (NBA) is the pre-eminent men's professional basketball league in North America, and is widely considered to be the premier men's professional basketball league in the world. NBA portal also provided management system to manage the event that held by NBA.

Optimum event management (OEM) is a web based event management system for dressage. OEM is experienced and knowledgeable in all aspects of Event Management about dressage. In the web portal of OEM, there is different information about dressage, venue lists and calendar is provided for customer to choose before held an affiliated \& unaffiliated dressage.

Table 1 shows the comparison of different system. Systems that are used to compare with E-EMNC are Eventbrite, National Basketball Association (NBA) and Optimum Event Management (OEM).

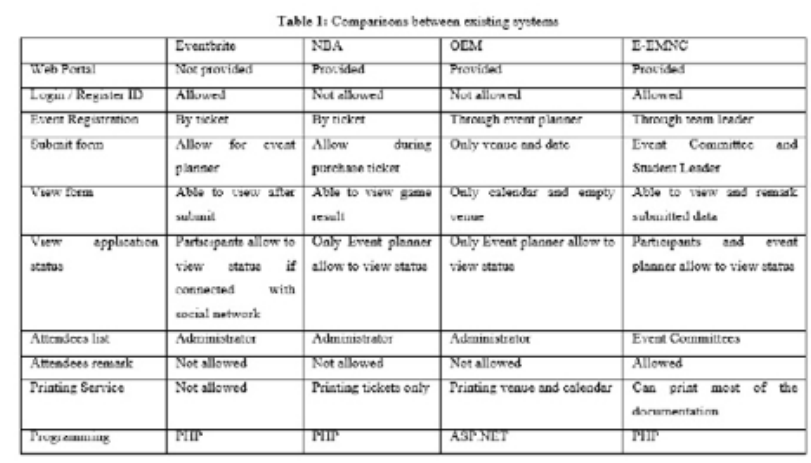

\section{Methodology}

System development life cycle methodologies provide what (processes and deliverable), how (techniques) and who (roles) for every typical role in a system development project which is suitable to apply in Web Based Management System of Enactus Malaysia National Cup (E-EMNC). This system uses waterfall model in its development whereby it attempts to balance the focus between processes and data. This waterfall model is chosen because it is a highly structured approach which requires documentation with clear project objectives and stable project requirements.

\section{A. Planning Phase}

During the planning phase, an interview section was conducted to obtain basic information and understand the problem from executive of 
Enactus Malaysia Foundation. Problem statement and background studies had been figure out in this phase.

\section{B. Analysis Phase}

In analysis phase, the system requirementand collection of data are important in order to develop the system correctly. This is done by interviewing Ms Afraz Said, Program \& Talent Development Senior Executive of Enactus Malaysia Foundation (EMF). The requirements are documented for further references. After gather of information, process model ia produced to show the way to operate system. The process model and data model includes the data flow diagram (DFD) and entity relationship diagram (ERC). The data flow diagram and entity relationship diagram of the system are drawn in order to show the system flow.

\section{Design Phase}

For the design phase, the user interface and database design were determined according to EMF requirements. The interface of each process of the system was determined to ensure the flow of the system is systematic. Furthermore, the interface shows how the user will move from one page to another in the system using navigation methods provided such as menus and buttons. Attractive design is conducted by using CSS and Bootstrap. Image materials such as logo, photo, and banner, are used but still follow the standard of Enactus.

\section{Implementation and Testing Phase}

In implementation and testing phase, the implementation of interface and source code of E-EMNC is built and so is the database of the system. The source code is reviewed in order for the system to work until the system is completed. The language and scripting used are HTML 5, CSS3, JavaScript, MySQL and PHP. Responsive web design such as Bootstrap is used as frontend framework for this system. The software which is used to develop this system is Photoshop CS6, notepad ++, and xamp.

\section{System Analysis and Design}

The analysis process would be explained in detail on the behavior of the system while the design of the system was produced a sketch actual system. This phase involved determining of the system architecture to show how the system development works. Data flow diagram (DFD), entity relationship diagram (ERD), flow charts are built in the model analysis. During analysis, data are collected on the available files. The design and analysis of the system will then be implemented and the actual system is built. It is concerned with issue relating to converting the final models into code and demonstrates the mapping between the models and the code. System requirements by using interviews conducted with users of the system is collected.

The following are the system requirements that were gathered from the previous interview with senior executive of Enactus Malaysia Foundation, Ms Afraz Said:

- Keep data of competition team records and relevant project details

- Enable student leader to access internet to apply for EMNC and fill in report.

- Platform for student leader to update member database via internet.

- Help event committee to manage EMNC with structured forms.

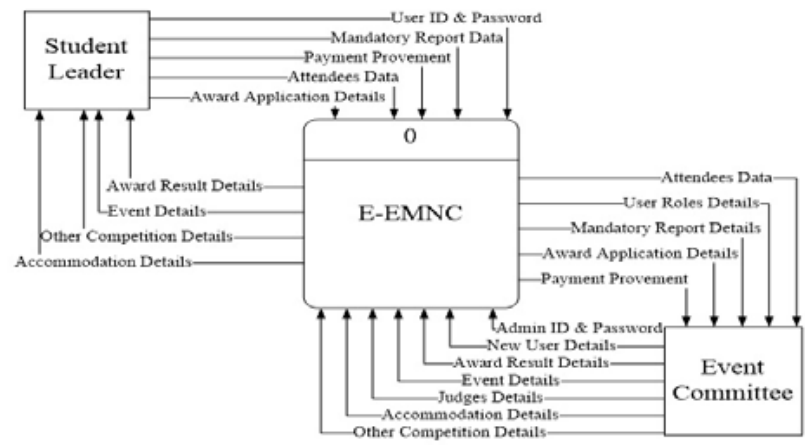

Figure 1: Context diagram of E-EMNC.

Figure 1 shows the context diagram for the entire system. There are two entity involved in the system which are student leader and event committee. Student leaders and event committees would log in the system with ID and password. Student leader need to fill in the mandatory report data, payment proven, attendee data and award application data. While event committees need to fill in the new user details, award result, event details, judge details, accommodation details and competition details.
In the other side, this system is designed to transmit the data that fill in by event committees and display it to student leaders. The data fill in by student leader also would be shown to event committees.

\section{Results}

Login page is set up in home page of E-EMNC and differentiate according to authentication of users, student leader and event committee. Users have to choose their roles before they enter their username and password. Success login will redirect user to their account page for further actions such as submit report, update attendees, and review details of national cup.

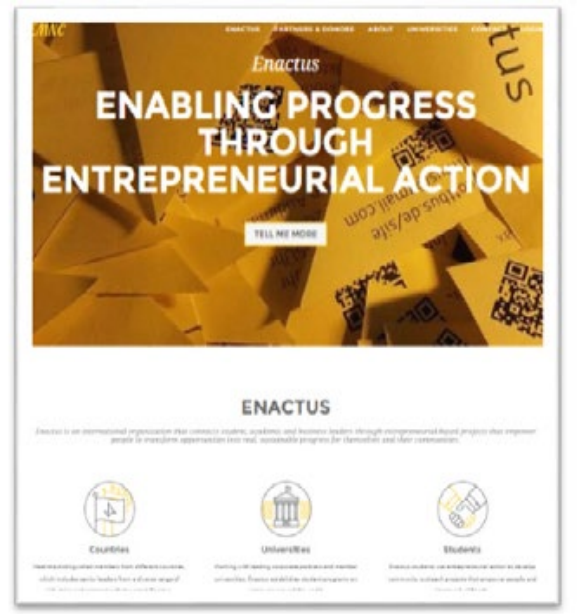

Figure 2: Main Page for the public

The Figure 2 shows the main page for web based management system of Enactus Malaysia National Cup. In the main page consists of information of EMNC and $\log$ in button. The authentication for this system can be differentiating into student leader and event committee, as shown in Figure 3.

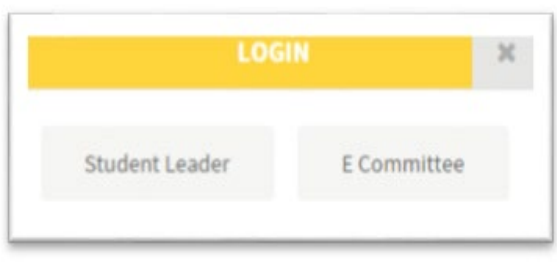

Figure 3: Pop up login interface for different user

Figure 4 shows after login by student leader, users would be navigated to their homepage. Same times happened to event coordinator. Student leaders are representative from each university. The menu bar is located on the left side and it contain sub menu for certain menu.




Figure 5 shows the home-page for end users. This has shown the complicated of the system with many kind of different report and other related document. There are seven main menus with total of 13 sub menus.



Figure 5: Interface of homepage of end-user, student leader

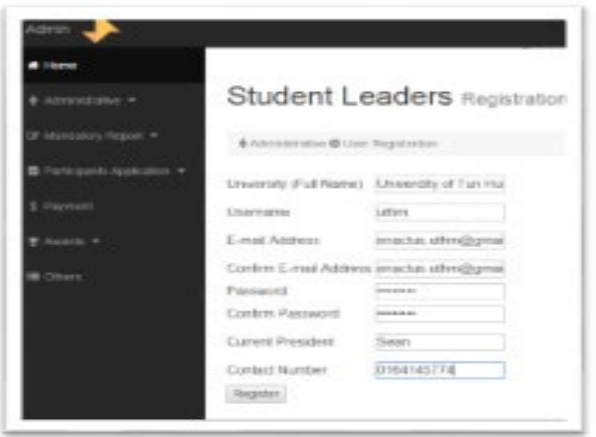

Figure 6: Regiatration form for new student leader to obtain new account

Figure 6 shows Registration form that assist on admin page. The registration form is located inside admin module to avoid spamming of account by student. For the new comer university, admin will register the new account for them.



Figure 7: Interface of Team Data Sheet with filled in information

Under sub-menu of mandatory report, there are four different reports which are team data sheet, active team sheet, project verification form and annual report. Figure 7 is the example of interface for Team Data Sheet.

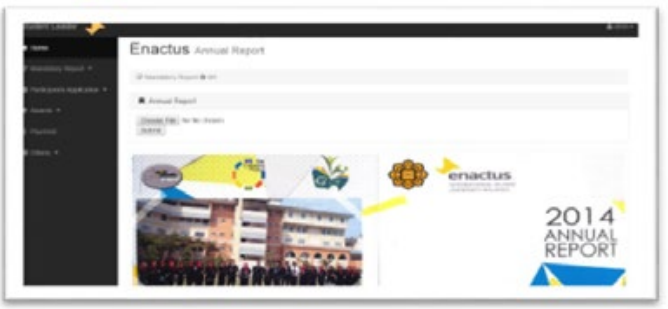

Figure 8: Image of report shown after success uploaded

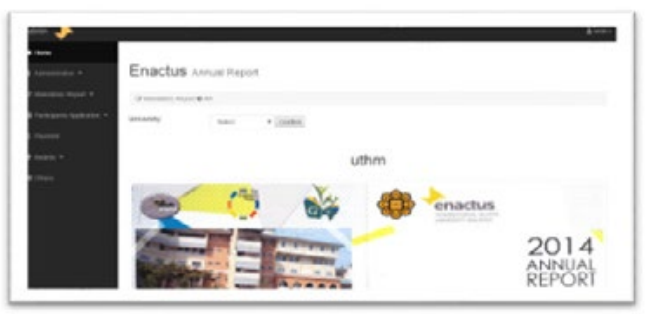

Figure 9: Interface of event committee to review on annual report.

There will be a slightly different for interface of event committee since event committee can check all the updated report of every registered university. By this, there will be a drop down bar for event committee to select the university. Example will be shown by comparing the same report between student leader and event committee through Figure 8 and Figure 9.

After the implementation phase, testing will be carried out to ensure the system fulfills the requirements. To perform the functional testing, test plan was prepared and developed within the resource constraints and the scope of the system. On the other hand, user acceptance testing is carried out by approaching to Enactus Malaysia Foundation for roles of event committee and student leader from each university.

There are only 10 testers from each category of users. 10 event committees are picked from previous national cup while 10 student leaders are picked among the university. Figure 10 and Figure 11 show the result and feedback from event committee. From the results, event committees are considered satisfy with the design and system that designed and developed for EMNC. Figure 12 and Figure 13 show the result and feedback from student leader.



Figure 10: User Interface Evaluation Result by Event Committee

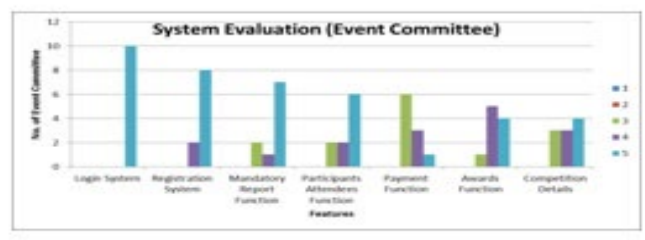

Figure 11: System Evaluation Result by Event Committee

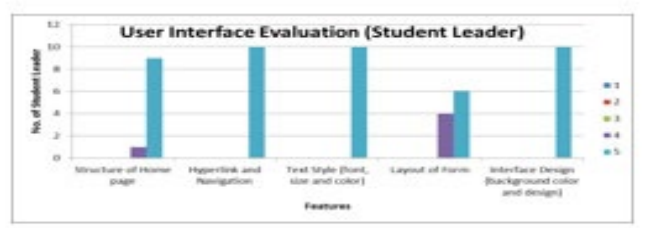

Figure 12: User Interface Evaluation Result by Student Leader



Figure 13: System Evaluation Result by Student Leader 
6. Conclusion and Future Work

Through this system, event committee no needs to rely on the previous traditional method which collect data from student through fax or email. Less time consume for pre-registration is needed since this system prepared every service that needed for EMNC.

Improvement can be applied to this system by enhance the performance, functionalities and interface. Firstly, this system can be improved by provide a scalable mandatory form which compile everything and student leader no need to click one by one. The performance is not limit to mandatory report only but also for attendee name list. This could enhance the user experiences by providing easier way for them. Besides, the payment system can be upgrade to e-payment system which completed payment by using Credit Card, PayPal or Visa Card. By so, student leader no need to use ATM machine for bank in. This could save a lot of time for student leader.

In short, E-EMNC is an online management system that allows users to submit report, complete registration, and receive information from Enactus Malaysia Foundation. This proposed system has been successfully developed and achieved its objective within the scope.

\section{Acknowledgement.}

This work is supported by Madam Hanayanti Binti Hafit as the supervisor and Faculty of Computer Science and Information Technology in University of Tun Hussein Onn Malaysia.

\section{References}

1. AECOM. (2014). Web-Based Program Management Systems. (n.d.). Retrieved from http://www.aecom. com/WhatWeDo/ProgramManagement/PracticeAreas/ WebbasedProgramManagementSystems?languagehoice=es_ ES\&Go=Go\&localeHidden=es_ES\&localeFlash=en_US

2. Enactus HQ. (2013). Enactus Team Handbook 2013 14. Springfield, MO USA. 